\title{
Modificação da virulência do virus do mixoma provocada pelos raios $\mathrm{X}$
}

\author{
pelo
}

\section{Dr. F. Rocha Lagôa}

(com 5 figuras no texto)

O vírus do mixoma dos coelhos possui um conjunto de propriedades que tornam, a nosso ver, particularmente interessante seu estudo. Assim temos:

a) - uma elevadíssima virulência para o animal sensível, bastando um único corpúsculo elementar para - na opinião de PARker (8), que realizou pesquisas estatísticas sôbre o assunto - obtermos uma infecção que evolui sempre fatalmente;

b) - contágio fácil, pois transmite-se diretamente pelo convívio em comum com animal enfêrmo, ou pela simples presença em local anteriormente ocupado por animal infetado ou, ainda, pela transmissão através de insetos, como demonstrou Aragão (I);

c) - especificidade absoluta para a espécie sensível, pois sòmente o coelho doméstico se infeta, ou então o coelho silvestre (Silvilagus minensis), ainda conforme demonstrou ARAGÃo (2);

d) - a curiosa propriedade citocinética que lhe faculta induzir multiplicações anormais em células oriundas do tecido mesodérmico, o que determina o aparecimento, nas lesões, de células típicas, chamadas "mixomatosas", onde se encontra um tipo de multiplicação (pseudomitose) semelhante às também presentes em certos tumores humanos, conforme verificações de MaGarinos ToRres (8);

e) - ausência de, até o presente momento, qualquer tipo de vacina eficaz para a proteção dos animais sensíveis, falhando todos os processos físicos e químicos habitualmente empregados em outros vírus e bactérias para a obtenção de vacinas. A inativação do vírus por qualquer dêsses agentes é sempre acompanhada da perda de sua antigenicidade (10).

A ausência, na bibliografia consultada, de qualquer referência a respeito da ação dos raios $\mathrm{X}$ sôbre o vírus do mixoma, induziu-nos a encetar o presente estudo, conhecida que é a capacidade dessas radiações de provocarem singulares modificações em animais (6), bactérias (4), enzimas e vírus (3).

Pareceu-nos que o estudo da ação dêsse agente físico sôbre o vírus do mixoma poderia nos proporcionar interessantes perspectivas para o conhecimento das variações de sua virulência, tornando-se assim pos- 
sível, graças à ação dissociativa dessas radiações, a obtenção de mutantes sem virulência, mas com poder antigênico íntegro, que seriam as condições ideais para obtenção de uma vacina eficaz contra a moléstia.

\section{MATERIAL E MÉTODOS}

O vírus do mixoma por nós utilizado foi purificado por uma técnica ligeiramente modificada da proposta por RIVERS e WARD (9), e que consiste no seguinte: o vírus, inoculado por escarificação no dorso epilado de coelhos, é colhido no quinto dia da inoculação da moléstia, retirando-se cuidadosamente o tecido mixomatoso da pele do animal doente, que é então triturado em gral estéril com alundum, adicionando-se ao ao mesmo uma solução-tampão de fosfato monopotássico Sorensen $\mathrm{pH}=7,1: 10 \mathrm{ml}$. para cada; após centrifuga-se o material repetidas vêzes em distintas velocidades afim de obter-se a deposição das impurezas existentes. Em seguida, seca-se o material no vácuo, em baixa temperatura, obtendo-se assim um pó, forma sob a qual foi o mesmo submetido à ação dos raios $\mathrm{X}$. A dosagem do vírus procedida no material assim preparado titulou $1 \times 10^{-6}$, conforme vê-se no gráfico I.

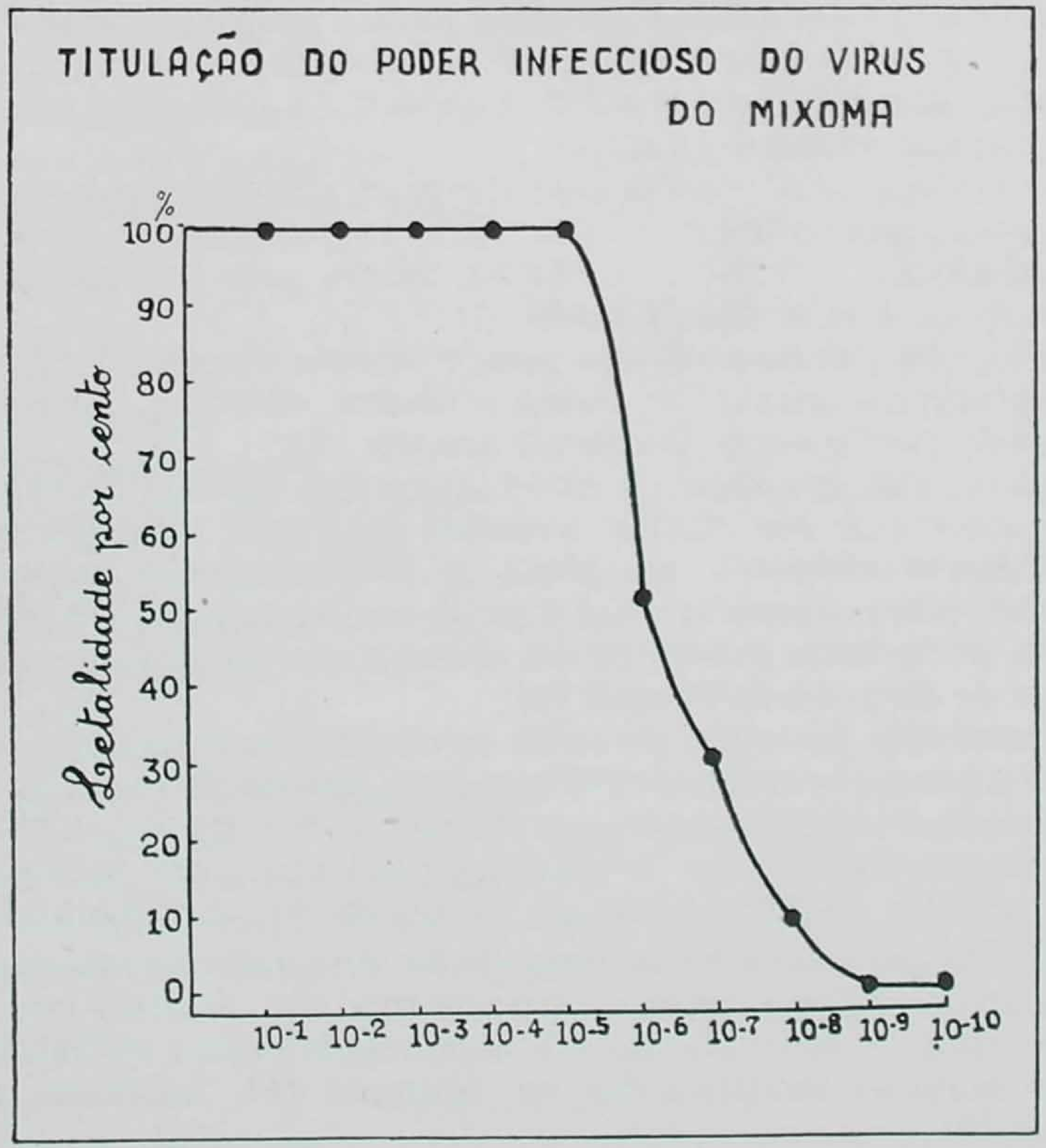

Gráfico I

$\mathrm{O}$ aparelho empregado para a produção de raios $\mathrm{X}$ foi um especial para contatoterapia, gentilmente cedido para êste estudo pelo Dr. $\mathrm{X}_{\mathrm{A}-}$ 
VieR De Oliveira, da "Philips S.A.", e que nos forneceu um rendimento de $1400 \mathrm{r}$ por minuto na distância de $3 \mathrm{~cm}$, que foi a deixada entre a ampola e o material a irradiar. A aferição foi realizada por aparelho Victoreen com câmara para 2500 r. O comprimento de onda das radiações fornecidas pelo aparelho foi de 0,247 A. O material, ao ser irradiado, encontrava-se em uma pequena placa de Petri, repousando sôbre gêlo, assegurando-se assim uma baixa temperatura durante a irradiação. O material, imediatamente após cada uma das irradiações - que foram intervaladas, - era depositado no refrigerador a -20òC, sendo efetuada uma suspensão no momento de ser utilizado em solução-tampão de $\mathrm{pH}=7,1$, usando-se a diluição de $1 \times 10^{-1}$, que era a inoculada no dorso epilado de coelhos, postos em observação, em isolamento adequado.

\section{RESULTADOS}

$\mathrm{O}$ vírus não revelou alterações em sua virulência até a dose de raios $\mathrm{X}$ incidida atingir a cifra de $294000 \mathrm{r}$. Verificou-se, então, que nem todos oS animais inoculados adquiriram a moléstia, evoluindo também a mesma, em alguns dos atacados, sob forma diversa da clássica, isto é, muito mais lentamente. A incidência de raios $\mathrm{X}$, ao atingir a concentração de $378000 \mathrm{r}$, fêz cessar por completo a atividade patogênica do vírus, o que nos mostrou encontrar-se êle inativado. No entanto, antes de alcançarem-se êsses resultados, a incidência da moléstia nos animais inoculados já se mostrava variável, alguns enfermando e outros não, como mostram os gráficos II e III.

CURVA DE INATIVAÇÃO DO VIRUS DO MIXOMA PELOS RAIOS $X$

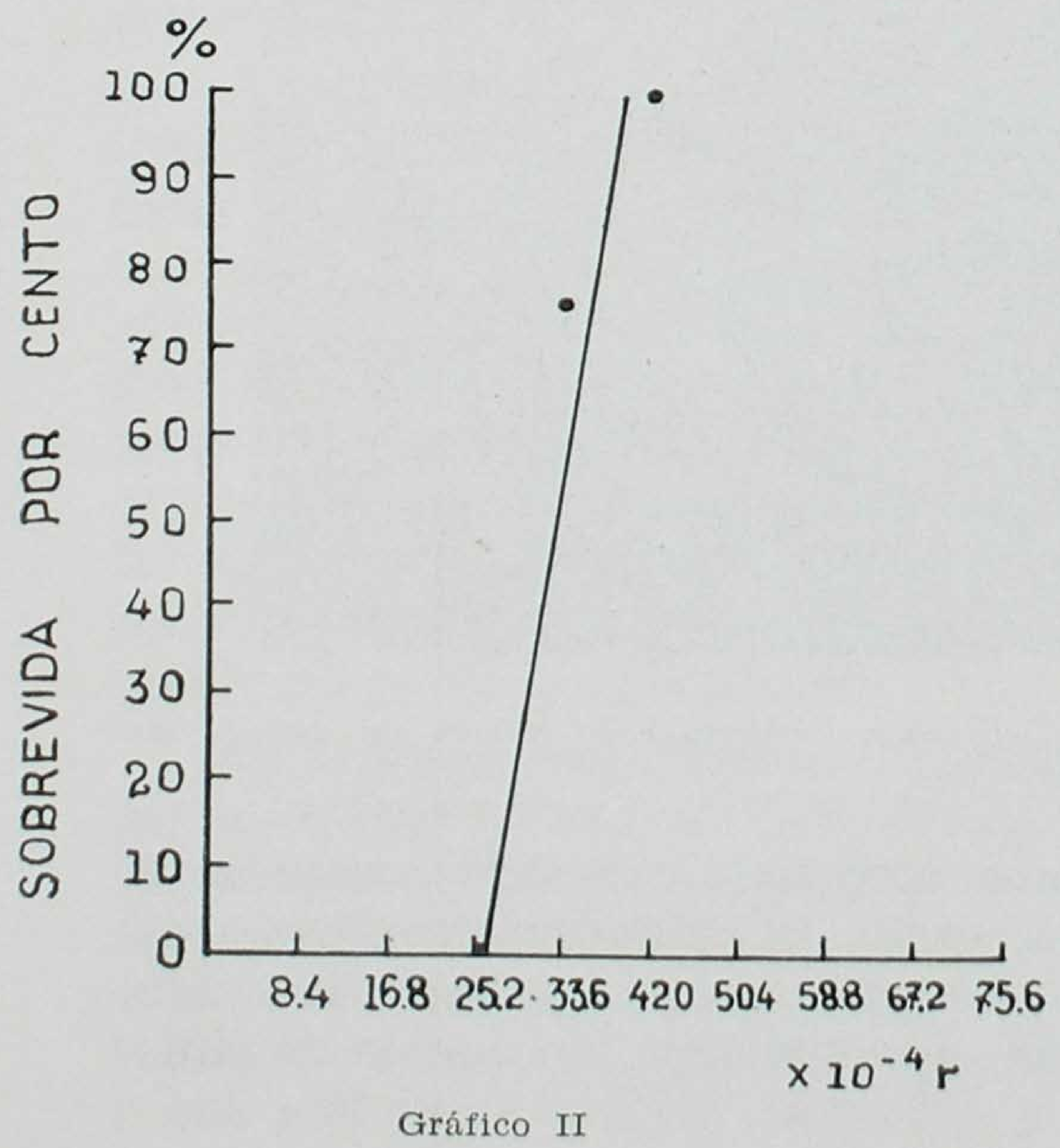

CURVA DE INATIVACÃO DO
VIRUS DO MIXOMA PELOS RAIOS X

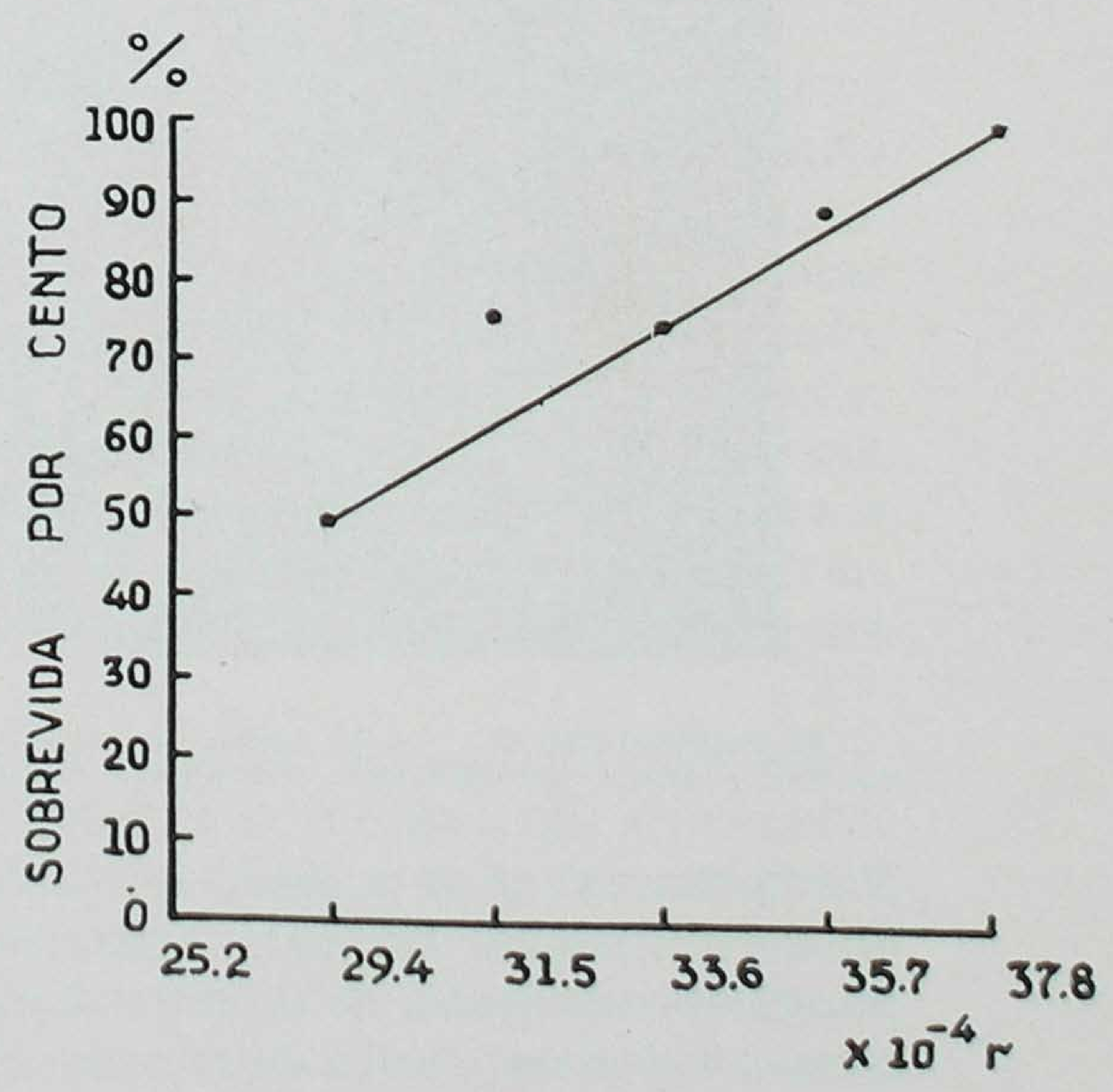

Gráfico III 
Os animais que contraíam a moléstia, quando inoculados com vírus irradiados com cifras menores que a última referida, apresentaram a moléstia com evolução extraordinàriamente mais lenta que a dos testemunhos. Nestes, a doença evoluia sempre fatalmente de 8 para 9 dias, enquanto que nos inoculados com vírus irradiado, entre 24 e 26 dias, o que revelou a existência de nítida atenuação da virulência do vírus.

Concordando com essas manifestações, as lesões mixomatosas encontradas nesses animais macroscòpicamente ou pelo exame histopatológico, foram muito mais discretas e menos extensas que as existentes nos testemunhas, como verifica-se pelas microfotografias IV e V.

A fig. IV corresponde a material colhido no ponto de inoculação da pele do coelho infetado com vírus normal e colhido no $8 .^{\circ}$ dia de evolução da moléstia, e a fig. V, a material colhido no ponto de inoculação (na região em que a lesão é mais intensa), proveniente de animal inoculado com vírus irradiado com $357000 \mathrm{r}$ e no $24 .^{\circ}$ dia de evolução da moléstia.

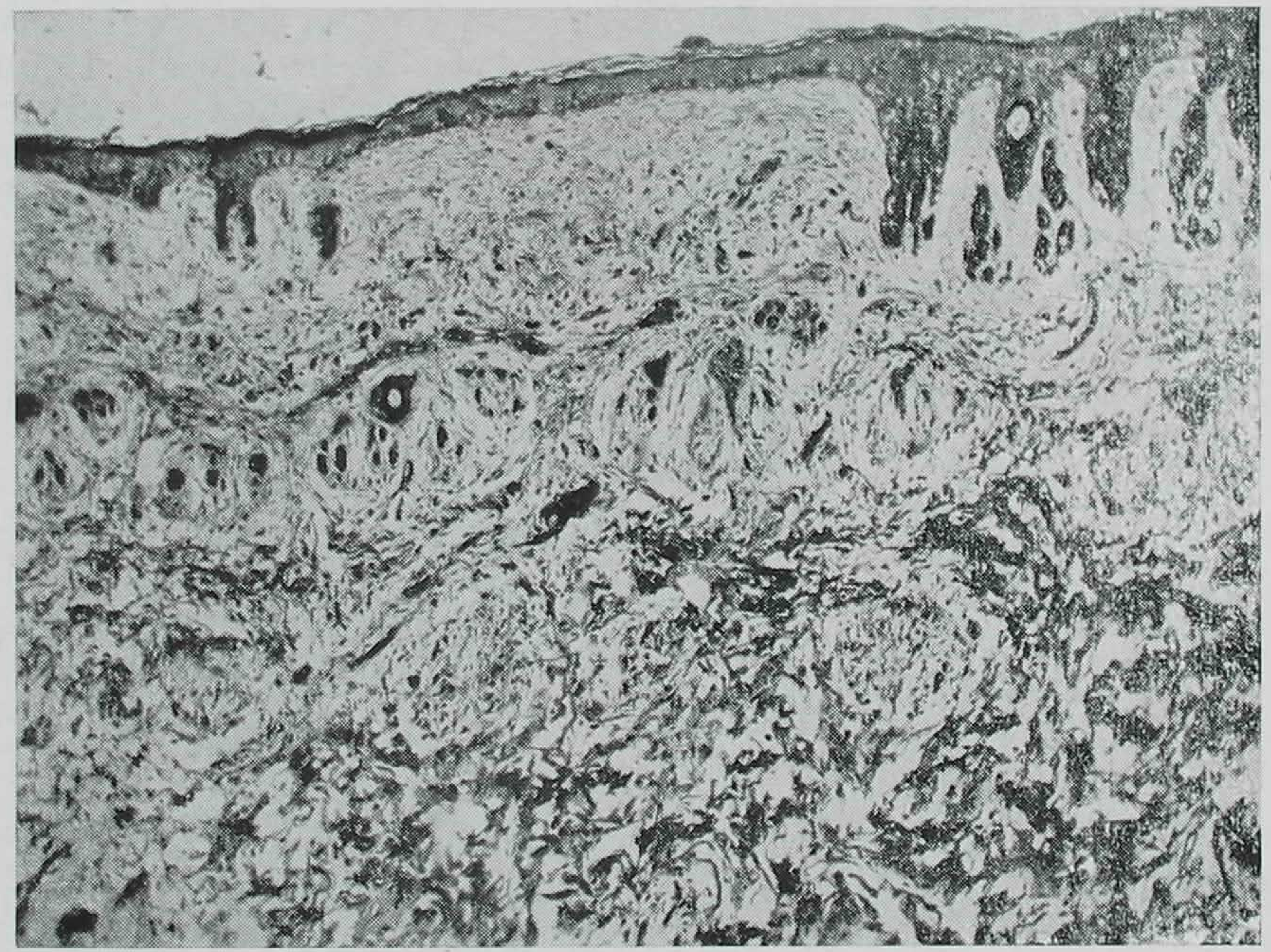

Microfotografia IV. - As lesốes do mixoma ocupam extensão considerável no derma, são aparentes lesōes da epiderme (necrose e espongiose).

Na figura IV vê-se a lesão de mixoma ocupando extensão considerável do derma, sendo também aparentes lesões da epiderme (necrose e espongiose) ; as lesões de mixoma típicas verificadas na fig. V são, contudo, menos extensas, tanto no derma como na epiderme, do que as demonstradas na fig. IV. 


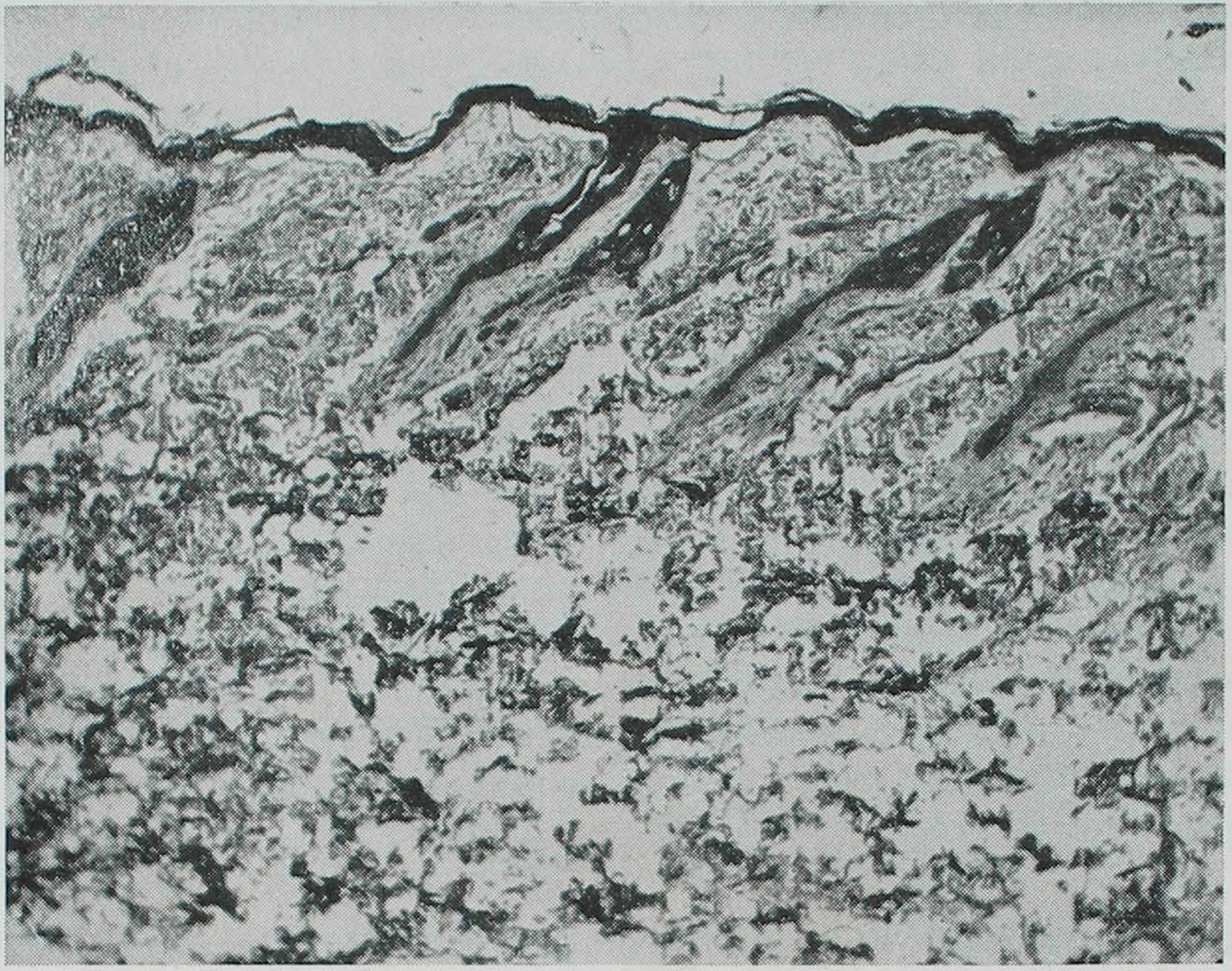

Microfotografia V. - Lesões de mixoma no derma discretas em relação às demonstradas na figura anterior. Nota-se ainda que as lesões da epiderme são menos intensas.

Devemos acrescentar que ambas provêm de regiões comparáveis, ou seja, daquelas em que mais acentuadas nos pareceram ser às lesões macroscópicas.

A evolução da moléstia em alguns animais inoculados com vírus, irradiado com as concentrações de 336000 e 357000 r, foi também muito mais lenta que a habitual, aparecendo os primeiros sintomas da moléstia nos $15 .^{\circ}$ e $16 .^{\circ}$ dias, sendo tôdas as manifestações mais discretas até alcançarem seu ápice nos $24 .^{\circ}$ dias, quando os animais morriam, com mixoma generalizado. No entanto, o tumor no ponto de inoculação, nessa ocasião, apresentava ainda proporções sempre bastante menores que o dos testemunhas, cujos primeiros sintomas surgem do 4.0 para o $5 .^{\circ}$ dia, agravando-se ràpidamente a moléstia, vindo o animal a morrer, sistemàticamente, nos $8 .^{0}-9 .^{\circ}$ dias com mixoma generalizado e grande tumor no ponto de inoculação.

Os animais sobreviventes, inoculados com vírus irradiado $378000 \mathrm{r}$, portanto com vírus inativado, foram submetidos, 7 dias após a primeira inoculação, a outra inoculação em idênticas condições; transcorridos 7 dias mais, a uma $3 .^{a}$ inoculação, e ao alcançar o $30 .^{\circ}$ dia da primeira inoculação, foram inoculados com vírus com virulência íntegra adquirindo todos, no entanto, a moléstia com evolução clássica e caracteres típicos, o que nos revelou não conservar o vírus do mixoma inativado pelos 
raios $\mathrm{X}$ as suas propriedades antigênicas, não protegendo, portanto, os animais aos quais são inoculados, contra uma inoculação posterior de vírus virulento.

A nosso ver, uma vacina eficaz contra a moléstia poderá ser obtida quando se conseguir uma atenuação da virulência do vírus em grau suficiente para que as lesões provocadas pela sua inoculação sejam sem conseqüências nocivas para o organismo inoculado. Esta atenuação deverá ,no entanto, permitir a integridade do poder antigênico do vírus, isto é, a sua capacidade de despertar reações favoráveis no organismo ao qual é inoculado.

Acreditamos ser possível a obtenção do vírus nessas condições, através da ação favorável dos raios $\mathrm{X}$, dependendo a concretização dêsses fatos apenas de serem superadas algumas dificuldades técnicas, como a separação do vírus suficientemente atenuado dos demais pouco atenuados, com a virulência íntegra ou completamente inativados. Presentemente, prosseguimos nessas pesquisas, esperando em breve alcançar algum resultado.

\section{CONCLUSÕES}

1) - os raios $X$ são capazes de provocar modificações na virulência do vírus do mixoma, atenuando-a ou abolindo-a, conforme sejam as doses, não tendo sido conseguidas, no entanto, mutantes do vírus;

2) - o vírus do mixoma inativado pelos raios $X$ não conserva suas propriedades antigênicas, não conferindo, portanto, aos animais nos quais são inoculados, uma proteção eficaz contra a infecção mixomatosa;

3) - a interpretação dos fatos observados através da teoria do tiro certeiro (Treffer theorie), proposta por JoRDAN (5), parece-nos perfeitamente aplicável ao presente estudo e elucidativa dos fatos observados;

a) - os elementos com virulência modificada seriam os atingidos em zona não vital mas suficientemente importante para influenciar a sua virulência;

b) - os vírus inativados foram os atingidos em zona vital;

c) - a incidência da moléstia, algumas vêzes com características típicas, em animais inoculados com vírus irradiado, mesmo com elevadas doses de raios $X$, seria conseqüência da presença de vírus não atingidos pelas radiações ou atingidos apenas em zonas não importantes, sem influência sôbre sua virulência.

4) - o vírus exposto à ação dos raios $X$ determinam lesões macro e microscópicas no ponto de inoculação evidentemente menos extensas e intensas do que as da doença típica, embora conservando elas os mesmos caracteres essenciais. 
5) - a atenuação da virulência do vírus do mixoma obtida pelos raios $\mathrm{X}$ indica-nos a possibilidade de vir a obter-se uma vacina eficaz contra a moléstia, utilizando-se esta ação favorável.

\section{SUMÁRIO}

Foi estudada a ação dos raios $\mathrm{X}$ sôbre o vírus sêco do mixoma dos coelhos. Ao atingir a incidência dos raios X a concentração de $294.000 \mathrm{r}$ até 378.00 , quando desapareceu tôda a atividade patogênica do vírus, nem todos os animais inoculados adquiriam a moléstia, passando a evoluir a mesma em alguns dêsses animais de forma muito mais lenta que a presente nas testemunhas. Concordando com esta sintomatologia, o exame histopatológico do material colhido no ponto de lesão mais intensa de animais atacados com mixoma de evolução lenta, revelou a existência de lesões menos extensas e intensas que aquelas presentes nos animais inoculados com o vírus normal, o que mostra terem os raios $\mathrm{X}$ determinado uma diminuição da virulência do vírus do mixoma, mas não uma mutação.

Os animais inoculados sucessivamente com vírus irradiado acima de $378.000 \mathrm{r}$, portanto inativados, foram, após 30 dias, inoculados com vírus de virulência íntegra, adquirindo, no entanto, a infecção mixomatosa com todos os caracteres típicos, o que revelou não conservar o vírus do mixoma inativado pelos raios $\mathrm{X}$ as suas propriedades antigênicas, não conferindo, portanto, proteção contra inoculações ulteriores de vírus mixomatoso virulento.

\section{BIBLIOGRAFIA}

1) ARAGÃo H. B. - 1927

O mixoma dos coelhos

Memórias Instituto Oswaldo Cruz, 20:25.

2) Aragão H. B. - 1943

O vírus do mixoma no coelho do mato

Memórias Instituto Oswaldo Cruz, 38:93.

3) LÉa D. Simith K. M. Holmer B. Marklan R. - 1944

Direct and indirect actions of radiations on viruses and enzymes. Parasitology, 36:110.

4) Haberiman S. Ellworth - 1939

The effect of X-rays on the dissociative rates of certain bacteria J. Bact., 38:237.

5) JORDAN P. - 1938

Uber die Elementarprogresse der biologischen Strahlenwirkung F. Radiológica 2 (12): 17. 
6) Muller J. H. - 1928

The production of mutations by $\mathrm{X}$-rays

Proc. Nat. Acad. Sci., 14:714.

7) Magarinos Torres C. B. -1944

Sôbre a hiperplasia celular no mixoma infectuoso do coelho. Memórias Instituto Oswaldo Cruz, 41:283.

8) PARKER R. - 1940

Studies of the infectious unit of myxoma

J. Exp. Med. 71:243.

9) RIVERS T. M. \& WARDIS M. - 1937

Infectious myxomatosis of rabbit. Prearation of elementary bodies and studies of serologically active materials associated with the disease J. Exp. Med., 66:1.

10) Rocha LAGÔA F. - 1947

Considerações sôbre o mixoma dos coelhos e suas relações com os tumores humanos.

A propósito da etiologia do câncer.

Brasil-Médico 51-52:3. 